\title{
Potential Predictors and Prevalence of Helicobacter pylori Infection Among Adult Patients With Dyspepsia: A Retrospective Study From Qatar
}

Vamanjore A. Naushad ${ }^{1,2,3}$, Nishan K. Purayil 1, 3, 2 , Ahmad Badi ${ }^{1,2}$, Prem Chandra ${ }^{4}$, Hassan O. Abuzaid 1, 3, 2 , Mohamed Milad Abuhmaira 1, 3, 2 , Abdo Lutf ${ }^{1,2}$, Firjeeth Paramba ${ }^{1,3}{ }^{3}$, Irfan Varikkodan ${ }^{1}$, AbdelNaser Y. Elzouki 1, 2, 3

1. Internal Medicine, Hamad Medical Corporation, Doha, QAT 2. Clinical Department, College of Medicine, Qatar University, Doha, QAT 3. Clinical Medicine, Weill Cornell Medicine - Qatar, Doha, QAT 4. Medical Research Center, Hamad Medical Corporation, Doha, QAT

Corresponding author: Vamanjore A. Naushad, nousha87@hotmail.com

\section{Abstract}

\section{Aim}

To study the prevalence of Helicobacter pylori (H. pylori) infection among dyspeptic patients of various ethnic origins in Qatar and determine the association between H. pylori infection and various demographic factors and endoscopic findings.

\section{Methods}

A retrospective data review was carried at Alkhor Hospital, Hamad Medical Corporation, Qatar. Adult patients who underwent endoscopy for the evaluation of dyspepsia between January 2011 to December 2017 were included. Patients who underwent endoscopy for reasons other than dyspepsia and those with incomplete data were excluded.

\section{Results}

Of the 638 subjects included, $58.9 \%$ were males, and the mean age of the subjects was 42.2 years (range 1879 years). Epigastric pain (80.6\%) was the most common symptom, followed by heartburn (26.2\%). Forty point nine percent (40.9\%) had a positive Campylobacter-like organism (CLO) test for H. pylori. A higher prevalence of $\mathrm{H}$. pylori infection was observed among subjects between $31-50$ years of age (43.6\%) and 1830 years (40.5\%), and in Asian (42.2\%) and Middle East and North African nationals (MENA) nationals (40\%). Among the endoscopic findings, esophagitis $(\mathrm{P}=0.002)$ and gastritis $(\mathrm{P}=0.001)$ showed a statistically significant correlation with $\mathrm{H}$. pylori positivity. Univariate regression analysis revealed an increased risk for H. pylori infection among all age groups except above 65 years, with an odds ratio (OR) of more than 2 in all the three age groups. Among various ethnicities, patients from Asia and MENA countries showed an increased risk of getting H. pylori infection (OR 1.16, 95\% CI; 0.77,1.75 and OR 1.06, 95\% CI 0.70,-1.61

Review began 06/15/2021 Review ended 06/28/2021 Published 07/06/2021

\section{() Copyright 2021}

Naushad et al. This is an open access article distributed under the terms of the Creative Commons Attribution License CC-BY 4.0., which permits unrestricted use, distribution, and reproduction in any medium, provided the original author and source are credited. respectively). The multivariable logistic regression analysis showed that subjects with endoscopic findings of esophagitis (adjusted OR 1.67, 95\%CI 1.19, 2.34; $\mathrm{P}=0.003$ ), gastritis (adjusted OR 1.79, 95\%CI 1.27, 2.57; $\mathrm{P}=0.001$ ), and duodenal ulcer (adjusted OR 2.41, 95\%CI 1.24, 4.70; $\mathrm{P}=0.010$ ) remained significantly associated with an increased risk of having $\mathrm{H}$. pylori infection.

\section{Conclusion}

The burden of H. pylori infection in patients with dyspepsia undergoing endoscopy is not low in Qatar. Less than 65 years of age, Asian nationals, and being from the MENA region were the demographic predictors for H. pylori infection. The finding of esophagitis, gastritis, and duodenal ulcer on endoscopy were independent endoscopic predictors for having $\mathrm{H}$. pylori infection.

Categories: Internal Medicine, Gastroenterology

Keywords: helicobacter pylori, h. pylori, clo test, dyspepsia, peptic ulcer disease, gastritis

\section{Introduction}

Helicobacter pylori (H. pylori) is a gram-negative, spiral-shaped bacteria that colonizes gastric mucosa, which is thought to be acquired in childhood. Infection with $\mathrm{H}$. pylori has been associated with peptic ulcer disease, chronic gastritis, and gastric malignancy [1-2]. In addition, H. pylori infection has also been reported in extra-digestive diseases such as hepatobiliary disease [3-4], idiopathic thrombocytopenic purpura (ITP) [5], ischemic heart disease (IHD) [6], and autoimmune thyroid disease [7]. The prevalence of $\mathrm{H}$. pylori infection is $80 \%-90 \%$ in developing countries, whereas, in developed nations, the prevalence is much 
lower, 20\%-50\% [8]. The prevalence rates in the western world decreased significantly in the last two decades. A meta-analysis by James et al. reported that H. pylori prevalence rates in Europe after 2000 decreased from $48.8 \%$ to $39.8 \%$, whereas, in northern America, it decreased from $42.7 \%$ to $26.6 \%$. In the Oceania region, the rates decreased from $26.6 \%$ to $18.7 \%$ after 2000 . However, the prevalence rates were nearly similar before and after 2000 in Asia (53.6 vs. 54.3\%) and Latin America (62.8\% vs 60.2\%) [9]. The possible causes for higher prevalence include low socioeconomic status and living in crowded households [10-12]. The transmission mode includes ingesting contaminated food or water or direct contact between humans [13-16]. In addition, iatrogenic transmission during dental procedures and endoscopies have been reported [17].

The data regarding $\mathrm{H}$. pylori infection in Qatar is limited with one study reporting a prevalence of $77 \%$ [18]. Qatar has a large expatriate population and not many studies have been done on the prevalence of H. pylori infection among various nationalities. Hence, we decided to compare H. pylori infection among patients from various ethnicities and age groups.

We aimed to evaluate the prevalence of H. pylori infection in patients with dyspepsia who underwent an endoscopy and study the association of $\mathrm{H}$. pylori infection with various demographic factors and endoscopic findings.

\section{Materials And Methods}

\section{Study design and setting}

A retrospective study was carried out at Alkhor Hospital, Hamad Medical Corporation, Qatar.

\section{Study subjects}

Patients above the age of 18 who underwent an endoscopy to evaluate dyspepsia between January 2011 and December 2017 were included. Patients with incomplete data and those who underwent endoscopy for reasons other than dyspepsia were excluded from the study. The first endoscopy was taken as index one for patients who had more than one endoscopy during the study period. Dyspepsia was defined according to National Institute for Health and Care Excellence (NICE) guidelines, which describes dyspepsia as a range of symptoms that include upper abdominal pain or discomfort, heartburn, gastric reflux, nausea, or vomiting [19].

\section{H. pylori diagnosis}

H. pylori was diagnosed by the Campylobacter-like organism (CLO) test done on the biopsy specimen. The CLO test is a commercially available gel-based rapid urease test. The presence of $H$. pylori urease enzyme in the gastric biopsy specimen converts the urea test reagent to ammonia, which increases the $\mathrm{pH}$, leading to color change in the $\mathrm{pH}$ monitor. These tests have 95\%-100\% specificity and sensitivity of $85 \%-95 \%$ [20].

\section{Data collection}

Data were retrieved from the medical records file and electronic database of patients using the health care number. Details about demographics, symptoms, smoking habits, alcohol consumption, nonsteroidal antiinflammatory drugs (NSAID) use, endoscopic findings, and the results of the CLO test for H. pylori were noted. For analytical purposes, we grouped the study subjects into five groups based on ethnicity: Qatari nationals, Middle East and North African (MENA) nationals, Asians (excluding Qatar and other nations included in the MENA group), Africans (excluding the nations included in the MENA group ), and others.

\section{Statistical analysis}

Descriptive statistics were used to summarize and determine the sample characteristics and distribution of participants' data. The normally distributed data and results were reported with mean and standard deviation (SD); the remaining results were reported with median and interquartile range (IQR). Categorical data were summarized using frequencies and proportions. The primary outcome variable in this study is the prevalence of positive H. pylori among dyspeptic patients undergoing endoscopy, and it was estimated and presented along with a $95 \%$ confidence interval $(\mathrm{CI})$. Associations between two or more qualitative data variables were assessed using the chi-square $(\chi 2)$ test or Fisher Exact test as appropriate. Quantitative data between the two independent groups (positive H. pylori vs negative H. pylori) were analyzed using unpaired $t$ or Mann Whitney U test as appropriate.

Univariate and multivariate logistic regression analysis (controlling and adjusted for potential predictors and confounders such as age, gender, ethnicities, comorbidities, presenting symptoms, and endoscopic findings) were applied to determine and assess the associations and predictive values of predictors and confounders stated above with a binary outcome variable risk of developing H. pylori infection. The results of logistic regression analyses were presented as odds ratio (OR) with corresponding 95\% CI. The receiver operating characteristic curve (ROC) was computed and constructed to evaluate and assess the predictive accuracy and discriminative ability of the developed logistic regression model (based on the predicted 


\section{Cureus}

probabilities) using potential significant variables found in the multivariate logistic regression model. All $\mathrm{P}$ values presented were two-tailed, and P values $<0.05$ were considered statistically significant. All statistical analyses were done using the statistical software packages SPSS version 27.0 (Armonk, NY: IBM Corp) and Epi-Info (Centers for Disease Control and Prevention, Atlanta, GA).

\section{Results}

\section{Demographic characteristics and symptoms}

After exclusion, 638 files were reviewed for final analysis. The mean age of the patients was 42.2 years (range $18-79$ ), and 376 (58.9\%) were males. The majority were in the $31-50$ years age group (55.3\%). Most of the study group consisted of patients from Asia 218 (34.2\%) and MENA countries (200; $31.3 \%$ ). There were 171 (26.8\%) Qatari nationals. Epigastric pain (80.6\%) was the most common symptom, followed by heartburn (26.2\%) in the overall study subjects. The detailed basic demographic characteristics and symptoms are summarized in Table 1 . 


\section{Cureus}

Variables

Number (\%) ( $\mathrm{N}=638$ )

Age group (in years)

18-30

$31-50$

51-65

$\geq 65$

Gender

Male

female

Nationality

Qatar

MENA

Asia

Africa

Others

Symptoms

Epigastric pain

Belching

Nausea

Vomiting

Heart Burn

Early satiety

Melena

Co-Morbidities

Hypertension

Diabetes Mellitus

Asthma

Coronary Artery Disease

Chronic Kidney Disease

Liver Disease

Medications

NSAID

Steroid
121 (19)

353 (55.3)

$134(21)$

$30(4.7)$

376 (58.9)

262 (41.1)

171 (26.8)

200 (31.3)

218 (34.2)

$36(5.6)$

$13(2.0)$

514 (80.6)

$56(8.8)$

65 (10.2)

61 (9.6)

167 (26.2)

15 (2.4)

$38(6)$

82 (12.9)

76 (11.9)

17 (2.7)

16 (2.5)

$5(0.8)$

$18(2.8)$

36 (5.6)

$3(0.5)$

TABLE 1: Baseline demographics and clinical characteristics

MENA: Middle East and North Africa; NSAID: nonsteroidal anti-inflammatory drug

Prevalence of $\mathbf{H}$. pylori infection

Out of 638 patients, 40.9\% (95\% CI 37.2, 44.8) had a positive CLO test for H. pylori, and 59.1 (377) had a 


\section{Cureus}

negative CLO test.

\section{H. pylori prevalence by gender, age group, and ethnicity}

There was no significant difference in H. pylori infection prevalence between males and females $(41.2 \%$ vs. $40.5 \%, \mathrm{P}=0.847$ ). A higher prevalence of $\mathrm{H}$. pylori infection was observed among subjects between $18-30$ years $(40.5 \%, 95 \%$ CI $32.2,49.4)$ ) and $31-50$ years $(43.6 \%$, 95\% CI 38.6, 48.8$)$ ) compared to other age groups. The rate of prevalence showed a decreasing trend in subjects above 50 years. However, the difference in prevalence among various age groups was not statistically significant ( $\mathrm{P}=0.147)$. On subanalyzing the prevalence in various ethnicities, the prevalence was higher in Asian nationals (42.2\%, 95\% CI 35.8,

48.8) and MENA nationals ( $40 \%$, 95\% CI 33.5, 46.9, ). Among Qatari nationals, the prevalence was $38.6 \%$. Even though the prevalence was found to be $50 \%$ in subjects from Africa, the total number of subjects in that group was significantly lower than in other groups. The difference in the prevalence of H.pylori infection among various ethnicities was statistically not significant (p .0678) (Table 2). 


\section{Cureus}

\begin{tabular}{|c|c|c|c|}
\hline Variables & $n / N$ & Percent Prevalence $(95 \% \mathrm{Cl})$ & P-value \\
\hline Overall & $261 / 638$ & $40.9(37.2,44.8)$ & \\
\hline \multicolumn{4}{|l|}{ Gender } \\
\hline Male & $155 / 376$ & $41.2(36.4,46.3)$ & 0.847 \\
\hline Female & $106 / 262$ & $40.5(34.7,46.5)$ & \\
\hline \multicolumn{4}{|l|}{ Age groups (years) } \\
\hline $18-30$ & 49/121 & $40.5(32.2,49.4)$ & 0.147 \\
\hline $31-50$ & $154 / 353$ & $43.6(38.6,48.8)$ & \\
\hline $51-65$ & $51 / 134$ & $38.1(30.3,46.3)$ & \\
\hline$>65$ & $7 / 30$ & $23.3(11.8,40.9)$ & \\
\hline \multicolumn{4}{|l|}{ Nationality } \\
\hline Qatar & $66 / 171$ & $38.6(31.6,46.1)$ & 0.678 \\
\hline MENA & $80 / 200$ & $40(33.5,46.9)$ & \\
\hline Asia & $92 / 218$ & $42.2(35.8,48.8)$ & \\
\hline Africa & $18 / 36$ & $50(34.5,65.5)$ & \\
\hline Others & $5 / 13$ & $38.4(17.7,64.5)$ & \\
\hline \multicolumn{4}{|l|}{ Symptoms } \\
\hline Epigastric pain & $211 / 514$ & $41.1(36.9,45.4)$ & 0.882 \\
\hline Belching & 19/56 & $33.9(22.9,47.0)$ & 0.266 \\
\hline Nausea & $26 / 65$ & $40(29.1,52.1)$ & 0.875 \\
\hline Vomiting & $22 / 61$ & $36.1(25.2,48.6)$ & 0.418 \\
\hline Heartburn & $68 / 167$ & $40.7(33.6,48.3)$ & 0.954 \\
\hline Early satiety & $6 / 15$ & $40(19.8,64.3)$ & 0.942 \\
\hline Melena & $17 / 38$ & $44.7(30.2,60.3)$ & 0.621 \\
\hline \multicolumn{4}{|l|}{ Comorbidities } \\
\hline Hypertension & $30 / 82$ & $36.6(27.1,47.4)$ & 0.394 \\
\hline Diabetes mellitus & $28 / 76$ & $36.8(26.9,48.1)$ & 0.442 \\
\hline Asthma & $5 / 17$ & $29.4(13.3,53.1)$ & 0.328 \\
\hline Coronary artery disease & $5 / 16$ & $31.3(14.2,55.6)$ & 0.426 \\
\hline Chronic kidney disease & $0 / 5$ & $0(0,43.5)$ & 0.062 \\
\hline Liver disease & $10 / 18$ & $55.6(33.7,75.4)$ & 0.200 \\
\hline \multicolumn{4}{|l|}{ Medications } \\
\hline Steroid & $0 / 3$ & $0(0,56.2)$ & 0.149 \\
\hline NSAID & $10 / 36$ & $27.8(15.9,44.1)$ & 0.099 \\
\hline
\end{tabular}

TABLE 2: Prevalence of $\mathrm{H}$. pylori-positive by demographics and other clinical characteristics $\mathrm{Cl}$ : confidence interval, $\mathrm{N}$ : total number, $\mathrm{n}$ : $\mathrm{H}$. pylori-positive

Correlation of $\mathbf{H}$. pylori infection and endoscopic findings 


\section{Cureus}

In the included study subjects, 595 (93.3\%) had an endoscopically identifiable cause of dyspepsia. Among 261 patients who were positive for H. pylori, only 12 (4.5\%) had normal endoscopy, whereas, among 377 patients who were negative for H.pylori, 31(8.2\%) had normal endoscopy.

In the overall study group, gastritis (67.2\%) was the most common endoscopic abnormality, followed by esophagitis (33.5\%). Gastric and duodenal ulcer was seen in $3.9 \%$ and $6.3 \%$ subjects, respectively. Carcinoma of the stomach was seen only in three subjects.

Among various endoscopic findings, esophagitis $(\mathrm{P}=0.002)$ and gastritis $(\mathrm{P}=0.001)$ showed a statistically significant correlation with $\mathrm{H}$. pylori positivity. Thirteen out of $25(52 \%, \mathrm{P}=0.032)$ subjects with gastric ulcer and 24 out of $39(61.5 \%, \mathrm{P}=0.017)$ subjects with duodenal ulcer had $\mathrm{H}$. pylori infection. Among three patients who had gastric cancer, only one had H. pylori positivity. Of patients with normal endoscopy, 27.9\% were positive for $\mathrm{H}$. pylori (Table 3).

\begin{tabular}{|c|c|c|c|c|}
\hline Endoscopic Findings & Overall Total $\mathrm{N}=638$ & H pylori-positive $\mathrm{N}=261$ & H pylori-negative 377 & P-value \\
\hline Normal endoscopy & $43(6.7)$ & $12(27.9)$ & 31 (72.1) & \\
\hline PUD & $595(93.3)$ & $249(41.8)$ & 346 (58.2) & 0.732 \\
\hline Esophagitis/GERD & 214 (33.5) & $106(49.5)$ & $108(50.5)$ & 0.002 \\
\hline Gastritis & $429(67.2)$ & $195(45.5)$ & 234 (54.5) & 0.001 \\
\hline Gastric ulcer & $25(3.9)$ & $13(52)$ & $12(48)$ & 0.250 \\
\hline Gastric cancer & $3(0.5)$ & 1 (33.3) & $2(63.7)$ & 0.789 \\
\hline Erosive duodenitis & $77(12.1)$ & 34 (44.2) & $43(55.8)$ & 0.437 \\
\hline Duodenal ulcer & $40(6.3)$ & $24(60)$ & $16(40)$ & 0.011 \\
\hline
\end{tabular}

\section{TABLE 3: Endoscopic findings in various groups}

PUD: peptic ulcer disease; GERD: gastroesophageal reflux disease

\section{Association of $\mathbf{H}$. pylori positivity with various predictors}

A univariate regression analysis was done for the following variables: gender, age groups, ethnic groups, comorbid conditions, symptoms, and endoscopic findings.

Regression analysis revealed an increased risk for H.pylori infection among all age groups except above 65 years of age, with an odds ratio (OR) of more than 2 in all three age groups. Among various ethnicities, patients from Asian, African, and MENA countries showed a positive risk of having H. pylori infection; however, it was statistically not significant.

Univariate regression analysis of endoscopic findings revealed that the highest predictor for $\mathrm{H}$. pylori infection was found to be duodenal ulcer (unadjusted OR 2.29 95\%CI 1.19, 4.39, $\mathrm{P}=0.011$ ) followed by gastritis (unadjusted OR 1.81 95\%CI 1.28, 2.56, $\mathrm{P}=0.001$ ) and esophagitis (unadjusted OR 1.70, 95\%CI 1.22, 2.38, $\mathrm{P}=0.002$ ), and all were statistically significant. Gastric ulcers on endoscopy were also seen as potential endoscopic predictors for $\mathrm{H}$. pylori infection; however, it was statistically insignificant $(\mathrm{P}>0.05)$. Also, patients having an abnormal finding of PUD on endoscopy were shown to be at an increased risk of having H. pylori infection (unadjusted OR 1.86, 95\%CI 0.94, 3.69, $\mathrm{P}=0.073$ ) as shown in Table 4.

\begin{tabular}{|l|l|l|l|}
\hline Variable & H. pylori-positive, $\mathbf{n}(\%)$ & Unadjusted odds ratio (OR) & $95 \%$ Cl for OR \\
\hline Gender & $155(41.2)$ & 1.0 (reference) & $0.70,1.33$ \\
Male & $106(40.5)$ & 0.97 & 0.847 \\
Female & & & \\
Nationality & $66(38.6)$ & 1.0 (reference) & 0.693 \\
Qatar & $80(40)$ & 1.06 & $0.70,1.61$ \\
MENA & & & 0.783
\end{tabular}




\section{Cureus}

\begin{tabular}{|c|c|c|c|c|}
\hline Asian & $92(42.2)$ & 1.16 & $0.77,1.75$ & 0.472 \\
\hline African & $18(50)$ & 1.591 .591 & $0.77,3.28$ & 0.208 \\
\hline Others & $5(38.4)$ & 0.68 & $0.17,2.73$ & 0.588 \\
\hline \multicolumn{5}{|l|}{ Age group (years) } \\
\hline$\geq 65$ & $7(23.7)$ & 1.0 (reference) & & \\
\hline $18-30$ & 49 (40.5) & 2.24 & $0.89,5.62$ & 0.087 \\
\hline $31-50$ & $154(43.6)$ & 2.54 & $1.06,6.08$ & 0.036 \\
\hline $51-65$ & $51(38.6)$ & 2.02 & $0.80,5.04$ & 0.132 \\
\hline \multicolumn{5}{|l|}{ Comorbidity* } \\
\hline Hypertension & $30(36.6)$ & 0.81 & $0.50,1.31$ & 0.394 \\
\hline Diabetes & $28(36.8)$ & 0.82 & $0.50,1.35$ & 0.442 \\
\hline Bronchial asthma & $5(29.4)$ & 0.59 & $0.21,1.71$ & 0.328 \\
\hline CAD & $5(31.3)$ & 0.65 & $0.22,1.89$ & 0.426 \\
\hline Liver disease & $10(55.6)$ & 1.84 & $0.72,4.72$ & 0.200 \\
\hline \multicolumn{5}{|l|}{ Symptomst } \\
\hline Epigastric pain & $211(41.1)$ & 1.03 & $0.69,1.54$ & 0.882 \\
\hline Belching & $19(33.9)$ & 0.72 & $0.42,1.29$ & 0.266 \\
\hline Nausea & $26(40)$ & 0.96 & $0.57,1.62$ & 0.875 \\
\hline Vomiting & $22(36.1)$ & 0.80 & $0.46,1.38$ & 0.418 \\
\hline Heartburn & $68(40.7)$ & 0.99 & $0.69,1.42$ & 0.954 \\
\hline Early satiety & $6(40)$ & 0.96 & $0.34,2.74$ & 0.942 \\
\hline Melena & $17(44.7)$ & 1.18 & $0.61,2.29$ & 0.621 \\
\hline \multicolumn{5}{|l|}{ Endoscopy Findings ${ }^{* *}$} \\
\hline PUD & $249(41.8)$ & 1.86 & $0.94,3.69$ & 0.073 \\
\hline Esophagitis & $106(49.5)$ & 1.70 & $1.22,2.38$ & 0.002 \\
\hline Varices & $8(57.1)$ & 1.96 & $0.67,5.70$ & 0.212 \\
\hline Hiatus hernia & $2(20)$ & 0.36 & $0.08,1.69$ & 0.175 \\
\hline Gastritis & 195 (45.5) & 1.81 & $1.28,2.56$ & 0.001 \\
\hline Gastric ulcer & $13(52)$ & 1.59 & $0.72,3.55$ & 0.250 \\
\hline Carcinoma stomach & $1(33.3)$ & 0.72 & $0.66,8.10$ & 0.789 \\
\hline Duodenitis & 34 (44.2) & 1.16 & $0.72,1.88$ & 0.537 \\
\hline Duodenal ulcer & $24(60)$ & 2.29 & $1.19,4.39$ & 0.011 \\
\hline
\end{tabular}

TABLE 4: Association of various predictors with H. pylori: logistic regression analysis

* absence of each respective comorbidity; $\dagger$ absence of each respective symptom; ${ }^{\star \star}$ abnormal; each respective endoscopy finding was considered as a reference group

PUD: peptic ulcer disease; CAD: coronary artery disease; CI: confidence interval; MENA: Middle East and North Africa

The multivariable logistic regression analysis showed that subjects with endoscopic findings of esophagitis 


\section{Cureus}

(adjusted OR 1.67, 95\%CI 1.19, 2.34; $\mathrm{P}=0.003$ ), gastritis (adjusted OR 1.79, 95\%CI 1.27, 2.57; $\mathrm{P}=0.001$ ), and duodenal ulcer (adjusted OR $2.41,95 \% \mathrm{CI} 1.24,4.70 ; \mathrm{P}=0.010$ ) remained significantly associated with increased risk of having $\mathrm{H}$. pylori infection after controlling and adjusting for all other potential confounder and predictors such as age, gender, ethnicities, comorbidities, presenting symptoms and other endoscopic findings shown in Table 4. Thereafter, we computed a prediction model using ROC analysis to evaluate the discriminative ability of potentially significant variables that indicated and demonstrated a modest fit (area under the curve (AUC) $=0.644,95 \%$ CI $0.61,0.69$ ) using potential predictors and risk factors observed in the developed multivariate logistic model as shown in Figure 1 and Table 5.

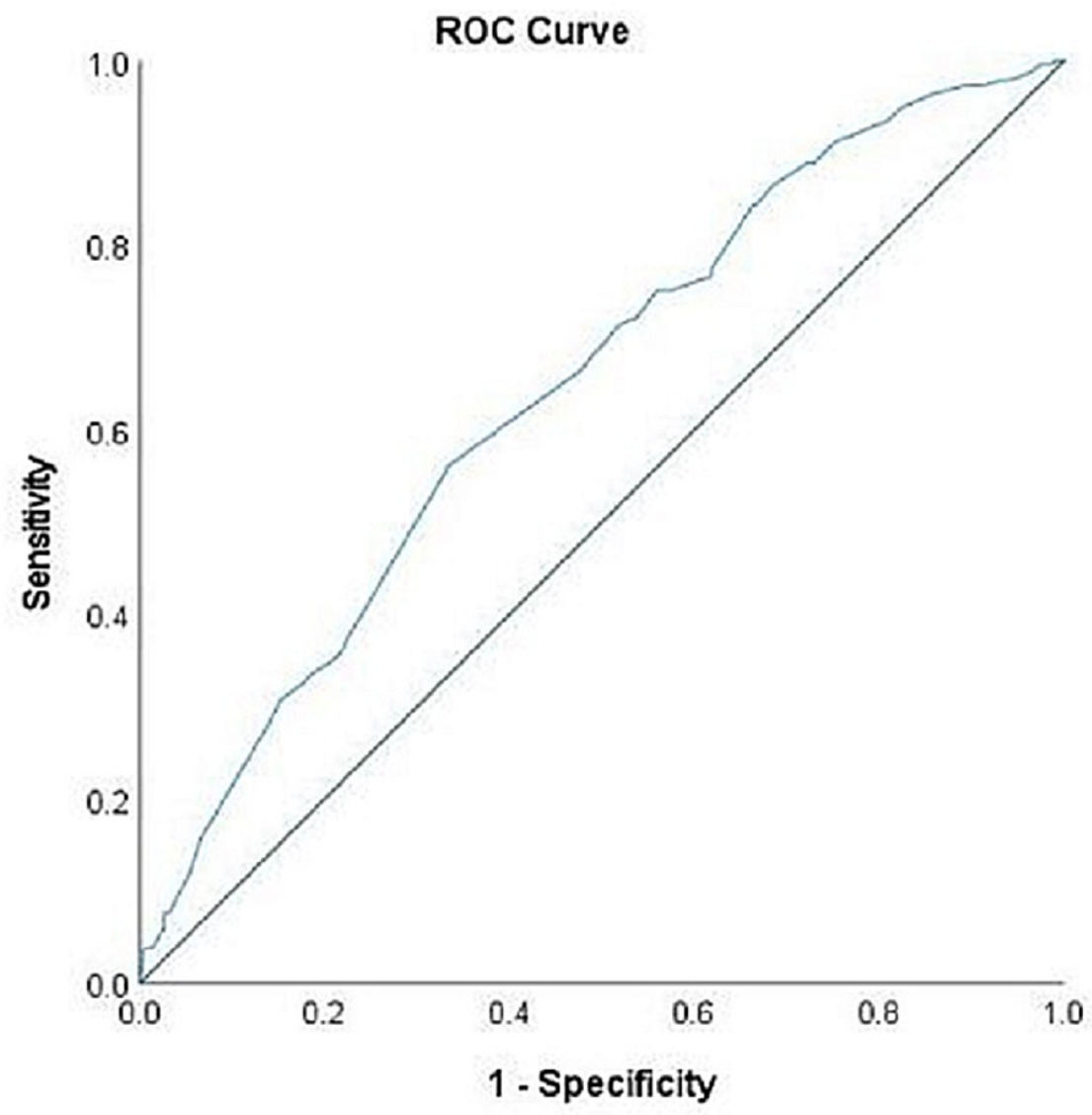

(Area under the curve-AUC $=0.644,95 \% \mathrm{CI} 0.61,0.69$ )

FIGURE 1: Receiver operating characteristic curve (ROC) to evaluate and assess the predictive accuracy of the developed logistic regression model (using the predicted probabilities) 


\section{Cureus}

\begin{tabular}{|c|c|c|c|c|}
\hline Variable & H. pylorl-positive, n (\%) & Adjusted odds ratio (OR) & $95 \% \mathrm{Cl}$ for OR & P-value \\
\hline \multicolumn{5}{|c|}{ Endoscopy Findings* } \\
\hline Esophagitis & $106(49.5)$ & 1.67 & $1.19,2.34$ & 0.003 \\
\hline Gastritis & $195(45.5)$ & 1.79 & $1.27,2.57$ & 0.001 \\
\hline Duodenal Ulcer & $24(60)$ & 2.41 & $1.24,4.70$ & 0.010 \\
\hline
\end{tabular}

\section{TABLE 5: Association of various predictors with $\mathrm{H}$. pylori: multivariate logistic regression}

analysis

* abnormal; each respective endoscopy finding was considered a reference group.

\section{Discussion}

The results showed that the overall prevalence of H. pylori infection was $40.9 \%$ in the study subjects, which is lower than that reported from Qatar in the past. Latif et al. studied the H. pylori infection in patients who underwent esophageal gastroduodenoscopy and reported that $77 \%$ of their study subjects were positive [18]. The higher prevalence in their study could be because they diagnosed $\mathrm{H}$. pylori infection by histopathology examination. In contrast, supporting our results, studies from other regions of the Middle East reported lower prevalence. Published reports from Saudi Arabia reported a varying range of $\mathrm{H}$. pylori infection prevalence in dyspeptic patients. Mohammad Akeel et al. [21] reported a prevalence of $46.5 \%$, whereas Ayoob et al. [22] found it to be $54.9 \%$. Higher prevalence rate than our results were reported from Kenya (71\%) [23], Nigeria (64\%) [24], Pakistan (57\%) [25], Cameron [26], and Turkey (65.9\%) [9].

Studies from the western world reported a wide varying range of prevalence. Lower prevalence rates are seen in countries like Switzerland (18.9\%), Sweden (26.2\%), and Denmark (22.1\%). When countries like the United Kingdom (35.5\%), Netherlands (35.5\%), and Germany (35.3\%) reported a moderate level of prevalence rates, Eastern European nations Poland (66.6\%), Romania (68.5\%), and the Russian Federation (78.5\%) reported a higher level of prevalence [9]. This wide range of differences in prevalence rates in these countries could be due to the difference in economic status and life habits.

We also examined the prevalence of $\mathrm{H}$. pylori infection in patients of various ethnicities. Our results showed that the prevalence among Qatari nationals was 38.6\%. Among expatriate populations, patients from Asia and MENA nations had a higher prevalence than Qatari citizens ( $42.2 \%$ and $40 \%$, respectively). A metaanalysis showed that central Asia had the highest prevalence rate (79.5\%) and southeast Asia showing the lowest prevalence (43.1\%). When Asian subcontinent countries, India( 63.5\%), Nepal ( 70.1\%), and Pakistan ( $81.0 \%$ ) reported higher prevalence rates, Southeast Asian nations, Malaysia ( 28.6\%) and Singapore ( 40.8\%) showed a lower prevalence rate [9]. The majority of Asian subjects in the present study were from India, Pakistan, Nepal, and Bangladesh, and hence, it is not surprising that the Asian cohort in our study had higher prevalence rates. Even though a higher prevalence was seen among the subjects from Africa, the number of subjects from these countries was much smaller than other groups. This is the first study from Qatar that compared H. pylori prevalence among various ethnic groups and its predictors. The significance of this comparison gains importance in view of that the state of Qatar is home to a large expatriate population from all over the world. A study from Kuwait that compared the prevalence among Kuwaiti nationals and expatriates reported an overall prevalence of $49.7 \% \mathrm{H}$. pylori infection in dyspeptic patients, and it was significantly higher in expatriates than Kuwaitis $(42.6 \%$ vs. $57.6 \% \mathrm{P}=0.004)$ [27]. However, the main difference from our study was that they included the expatriate population as a single cohort.

On analyzing the prevalence of $\mathrm{H}$. pylori infection among various age groups, it was found that the prevalence was higher in subjects between 18 and 50 years of age (40.5\% in 18 -30 years and $43.6 \%$ in 31-50 years). This is much higher than that reported by Corojan et al. who reported it to be around $11 \%$ in $18-29$ years and $20 \%-24 \%$ in those aged $30-59$ years ago [28].

We studied the possible predictors for $\mathrm{H}$ pylori infection using various variables. Our results showed that gender has no significant influence on H. pylori infection, whereas age below 65 years has a positive association with $\mathrm{H}$. pylori infection. In contrast, a meta-analysis by Ana Ferro reported that men had a significantly higher odds ratio and prevalence ratio of H. pylori infection compared to women [29]. Past published studies have shown a significant association between age and H. pylori infection [30-31].

The univariate analysis also revealed a positive association for $\mathrm{H}$. pylori infection with ethnicity. Patients from Asia and the MENA region had a positive association for $\mathrm{H}$. pylori infection. Even though our results showed African ethnicity as a predictor for $\mathrm{H}$. pylori infection, this can not be taken into consideration, as 
their sample size was small.

Multivariate analysis was done for predictors, which showed a significant positive association in univariate regression analysis, and it revealed that esophagitis, gastritis, and duodenal ulcer on endoscopy as independent predictors for $\mathrm{H}$. pylori infection.

The present study has some limitations. First, since H. pylori were diagnosed by the CLO test, which is less sensitive than biopsy, this might have excluded some patients with H. pylori infection. Second, subjects from the western world and African nations (excluding MENA countries) in the study population were low, and hence the association of predictors for $\mathrm{H}$. pylori infection in these ethnic groups was not possible. Lastly, gastritis was diagnosed based on endoscopic appearance and not by histopathology, which might have overestimated the diagnosis.

\section{Conclusions}

In conclusion, the prevalence of $\mathrm{H}$. pylori infection among adult patients with dyspepsia is not low in the Qatar population. The prevalence is higher in the 18-50 year age group and in subjects from Asia and the MENA region. Less than 65 years of age, Asian nationals, and being from the MENA region were common predictors for having H. pylori infection. On endoscopy, having a finding of PUD itself is found to be a predictor for H. pylori infection with esophagitis, gastritis, and duodenal ulcer having the highest risk.

\section{Additional Information}

\section{Disclosures}

Human subjects: Consent was obtained or waived by all participants in this study. Institutional Review Board, Medical Research Center, Hamad Medical Corporation issued approval 14105/14. Waiver of consent was obtained from the Institutional Review Board of Medical Research Center, Hamad Medical Corporation. Animal subjects: All authors have confirmed that this study did not involve animal subjects or tissue. Conflicts of interest: In compliance with the ICMJE uniform disclosure form, all authors declare the following: Payment/services info: All authors have declared that no financial support was received from any organization for the submitted work. Financial relationships: All authors have declared that they have no financial relationships at present or within the previous three years with any organizations that might have an interest in the submitted work. Other relationships: All authors have declared that there are no other relationships or activities that could appear to have influenced the submitted work.

\section{References}

1. Wotherspoon AC, Ortiz-Hidalgo C, Falzon MR, Isaacson PG: Helicobacter pylori-associated gastritis and primary B-cell gastric lymphoma. Lancet. 1991, 338:1175-6.

2. Parsonnet J: Helicobacter pylori and gastric cancer. Gastroenterol Clin North Am. 1993, 22:89-104. 10.1016/S0889-8553(21)00265-X

3. Mishra RR, Tewari M, Shukla HS: Association of Helicobacter pylori infection with inflammatory cytokine expression in patients with gallbladder cancer. Indian J Gastroenterol. 2013, 32:232-5. 10.1007/s12664-0130321-6

4. Polyzos SA, Kountouras J, Papatheodorou A, et al.: Helicobacter pylori infection in patients with nonalcoholic fatty liver disease. Metabolism. 2013, 62:121-6. 10.1016/j.metabol.2012.06.007

5. Payandeh M, Sohrabi N, Zare ME, Kansestani AN, Hashemian AH: Platelet count response to Helicobacter pylori eradication in Iranian patients with idiopathic thrombocytopenic purpura. Mediterr J Hematol Infect Dis. 2012, 4:e2012056. 10.4084/MJHID.2012.056

6. Eskandarian R, Ghorbani R, Shiyasi M, Momeni B, Hajifathalian K, Madani M: Prognostic role of Helicobacter pylori infection in acute coronary syndrome: a prospective cohort study. Cardiovasc J Afr. 2012, 23:131-5.

7. Shi WJ, Liu W, Zhou XY, Ye F, Zhang GX: Associations of Helicobacter pylori infection and cytotoxinassociated gene A status with autoimmune thyroid diseases: a meta-analysis. Thyroid. 2013, 23:1294-300. 10.1089/thy.2012.0630

8. Suerbaum S, Michetti P: Helicobacter pylori infection. N Engl J Med. 2002, 347:1175-86. 10.1056/NEJMra020542

9. Hooi JKY, Lai WY, Ng WK, et al.: Global prevalence of Helicobacter pylori infection: systematic review and meta-analysis. Gastroenterology. 2017, 153:420-9. 10.1053/j.gastro.2017.04.022

10. Muhsen Kh, Athamna A, Athamna M, Spungin-Bialik A, Cohen D: Prevalence and risk factors of Helicobacter pylori infection among healthy 3- to 5-year-old Israeli Arab children. Epidemiol Infect. 2006, 134:990-6. 10.1017/S0950268806006030

11. Muhsen K, Athamna A, Bialik A, Alpert G, Cohen D: Presence of Helicobacter pylori in a sibling is associated with a long-term increased risk of H. pylori infection in Israeli Arab children. Helicobacter. 2010, 15:108-13. 10.1111/j.1523-5378.2010.00746.X

12. Weyermann M, Adler G, Brenner H, Rothenbacher D: The mother as source of Helicobacter pylori infection . Epidemiology. 2006, 17:332-4. 10.1097/01.ede.0000201257.31155.a0

13. Cheng H, Hu F, Zhang L, et al.: Prevalence of Helicobacter pylori infection and identification of risk factors in rural and urban Beijing, China. Helicobacter. 2009, 14:128-33. 10.1111/j.1523-5378.2009.00668.x

14. Klein PD, Graham DY, Gaillour A, et al.: Water source as risk factor for Helicobacter pylori infection in Peruvian children. Lancet. 1991, 337:1503-6. 10.1016/0140-6736(91)93196-g 
15. Hopkins RJ, Vial PA, Ferreccio C, et al.: Seroprevalence of Helicobacter pylori in Chile: vegetables may serve as one route of transmission. J Infect Dis. 1993, 168:222-6. 10.1093/infdis/168.1.222

16. Goodman KJ, Correa P, Tenganá Aux HJ, et al.: Helicobacter pylori infection in the Colombian Andes: a population-based study of transmission pathways. Am J Epidemiol. 1996, 144:290-9. 10.1093/oxfordjournals.aje.a008924

17. Brown LM: Helicobacter pylori: epidemiology and routes of transmission. Epidemiol Rev. 2000, 22:283-97. 10.1093/oxfordjournals.epirev.a018040

18. Latif A, Azadeh B: Helicobacter pylori gastritis in Qatar a clinico-histopathological study . Qatar Med J. 2002, 2:[Epub]. 10.5339/qmj.2002.2.10

19. National Institute for Health Care and Excellence (NICE). Dyspepsia and gastro-oesophageal reflux disease in adults. (2015). https://www.nice.org.uk/guidance/qs96.

20. Wang YK, Kuo FC, Liu CJ, et al.: Diagnosis of Helicobacter pylori infection: current options and developments. World J Gastroenterol. 2015, 21:11221-35. 10.3748/wjg.v21.i40.11221

21. Akeel M, Elmakki E, Shehata A, Elhafey A, Aboshouk T, Ageely H, Mahfouz MS: Prevalence and factors associated with H. pylori infection in Saudi patients with dyspepsia. Electron Physician. 2018, 10:7279-86. 10.19082/7279

22. Ayoola AE, Ageely HM, Gadour MO, Pathak VP: Prevalence of Helicobacter pylori infection among patients with dyspepsia in South-Western Saudi Arabia. Saudi Med J. 2004, 25:1433-1438.

23. Shmuely H, Obure S, Passaro DJ, et al.: Dyspepsia symptoms and Helicobacter pylori infection, Nakuru, Kenya. Emerg Infect Dis. 2003, 9:1103-7.

24. Jemilohun AC, Otegbayo JA, Ola SO, Oluwasola OA, Akere A: Prevalence of Helicobacter pylori among Nigerian patients with dyspepsia in Ibadan. Pan Afr Med J. 2010, 6:18.

25. Siddiqui B, Yakoob J, Abbas Z, Azmat R, Fatima SS, Awan S: Distribution of Helicobacter pylori infection and abnormal body-mass index (BMI) in a developing country. J Infect Dev Ctries. 2018, 12:342-6. 10.3855 /jidc. 10051

26. Kouitcheu Mabeku LB, Noundjeu Ngamga ML, Leundji H: Potential risk factors and prevalence of Helicobacter pylori infection among adult patients with dyspepsia symptoms in Cameroon. BMC Infect Dis. 2018, 18:278. 10.1186/s12879-018-3146-1

27. Alazmi WM, Siddique I, Alateeqi N, Al-Nakib B: Prevalence of Helicobacter pylori infection among new outpatients with dyspepsia in Kuwait. BMC Gastroenterol. 2010, 10:14. 10.1186/1471-230X-10-14

28. Corojan AL, Dumitrașcu DL, Ciobanca P, Leucuta DC: Prevalence of Helicobacter pylori infection among dyspeptic patients in Northwestern Romania: a decreasing epidemiological trend in the last 30 years. Exp Ther Med. 2020, 20:3488-92. 10.3892/etm.2020.9024

29. Ferro A, Morais S, Pelucchi C, et al.: Sex differences in the prevalence of Helicobacter pylori infection: an individual participant data pooled analysis (StoP Project). Eur J Gastroenterol Hepatol. 2019, 31:593-8. 10.1097/MEG.0000000000001389

30. Tadesse E, Daka D, Yemane D, Shimelis T: Seroprevalence of Helicobacter pylori infection and its related risk factors in symptomatic patients in southern Ethiopia. BMC Res Notes. 2014, 7:834. 10.1186/1756-05007-834

31. Mathewos B, Moges B, Dagnew M: Seroprevalence and trend of Helicobacter pylori infection in Gondar University Hospital among dyspeptic patients, Gondar, North West Ethiopia. BMC Res Notes. 2013, 6:346. 10.1186/1756-0500-6-346 